\title{
Optimization of staining with SYTO 9/propidium iodide: interplay, kinetics and impact on Brevibacillus brevis
}

\author{
Ying Deng1', Lili Wang', Yujia Chen' \& Yan Long*, (iD) \\ ${ }^{1}$ Guangdong Key Laboratory of Environmental Pollution \& Health, School of Environment, Jinan University, Guangzhou, 510632, China; *Author for correspondence: \\ icarolyn@163.com
}

BioTechniques 69: 89-98 (August 2020) 10.2144/btn-2020-0036

First draft submitted: 30 March 2020; Accepted for publication: 27 April 2020; Published online: 12 May 2020

\section{ABSTRACT}

Fluorophores SYTO 9 and propidium iodide (PI) are extensively applied in medicine, food industry and environmental monitoring to assess the viability of bacteria. However, the actual performance of these dyes remains largely unknown. In addition, their effects on the physiology of cells have not been elucidated. Here we characterized the effects of these two dyes on Brevibacillus brevis under optimized staining. We found that SYTO 9 entered cells continuously while PI tended to adhere to the cell wall before entering the cell. In addition, results showed that a high amount of the dyes altered the physicochemical properties of membranes, improving their breakthrough. These results provide new perspectives and ideas for improving the characterization of bacterial viability using flow cytometry.

\section{METHOD SUMMARY}

Investigation of the interplays among dyes, the targeted organism and the staining conditions was achieved by flow cytometry. Quantification of dyes was performed by measuring the absorbance using derivative spectrometry. Variations in phospholipid synthesis and cell morphology after excessive dye exposure were determined by gas chromatography-tandem mass spectrometry and scanning electronic microscopy.

KEYWORDS:

Brevibacillus brevis $\bullet$ derivative spectrometry $\bullet$ flow cytometric $\bullet$ kinetics $\bullet$ propidium iodide $\bullet$ SYTO 9

Owing to their high affinity for DNA, SYTO 9 and propidium iodide (PI) are widely used in bacterial viability tests [1,2]. Both live and dead prokaryotic and eukaryotic cell membranes are permeable to SYTO 9, which binds DNA and RNA, emitting green fluorescence. PI only permeates dead or damaged cells, emitting a red fluorescence [3]. Cell labeling efficiency is determined by factors that include the reagent's binding affinity to cells [4], physiological state of the cells [5,6], reagent concentration [7], temperature and incubation time [8].

Gram-negative bacteria, including Pseudomonas aeruginosa and Escherichia coli have been reported to resist SYTO 9 entry due to their cell membrane characteristics [4,9]. Brevibacillus brevis, a gram-positive bacterium, is more adsorptive to lipophilic substances and sensitive to toxic agents due to its thicker peptidoglycan layer and lack of an outer membrane. The peptidoglycan layer exhibits a $30-\AA$ diameter helical periodicity and a 70- $\AA$ diameter pore in each hexagonal unit [10]. Thus small molecules can diffuse across the cell wall, including benzo[a]pyrene [11], pyrene [12], tricresyl phosphate [13], decabromodiphenyl ether [14] and triphenyltin [15]. The features of the $B$. brevis cell wall and membrane make it suitable for studies of the uptake of potentially toxic stains and how they affect cell physiology.

The interaction between dyes, the cell, and the staining conditions are important in flow cytometry (FCM) where speed, the sensitivity of single-cell analysis and the stability of the dye are critical factors for an experiment's success [2]. By setting the flow rate and displaying the detection time during cell counting, FCM is convenient and time-saving compared with traditional plate counting [16,17]. In addition, measurement of dyes has an important application in techniques like liquid/gas chromatography and mass spectrometry [18,19]. However, the application of labeling dyes is not productive if the dyes are of unknown composition or if their adsorption/emission spectra have significant overlap. The Nanodrop is a full-spectrum $(220-750 \mathrm{~nm})$ spectrophotometer that requires only $1 \mu$ l of sample to make highly accurate and reproducible reads. It is a simple, convenient and low-cost approach for detecting dyes' spectral characteristics and can therefore quantify various dyes by analyzing their derivative spectra [20-22].

Phospholipids are an important constituent of plasma membranes [23]. Modification of plasma membrane fatty acid composition and content are sufficient to affect membrane transport, and cellular membranes' fluidity can be altered by changing fatty acid saturation [24]. In turn, the fluidity of the membrane directly affects its permeability to external molecules [25]. In addition, membrane lipid homeostasis influences intracellular transport and metabolism [26]. 
Here we investigated the uptake of potentially toxic stains and their impacts on cell physiology. We used derivative spectrometry to quantify binary solutions in extracellular view, and variations in phospholipid synthesis and cell morphology after staining with excessive amounts of dye were also evaluated. Our findings offer novel insights into SYTO 9 and PI uptake kinetics and impacts in B. brevis and lay the foundation for future studies on bacterial viability during flow cytometry.

\section{Materials \& methods}

\section{Chemicals \& reagents}

The BacLight LIVE/DEAD bacterial viability kit (Thermo Fisher Scientific, L7012) was used in all experiments. The kit is comprised of SYTO 9 and PI nucleic acid dyes, which were dissolved in DMSO at stock concentrations of 3.34 and 20 mM, respectively. The bacterial nutrient broth was composed of $5 \mathrm{~g} / \mathrm{l}$ beef extract, $10 \mathrm{~g} / \mathrm{l}$ peptone and $5 \mathrm{~g} / \mathrm{l} \mathrm{NaCl}$.

\section{Strain \& growth conditions}

B. brevis was isolated by our group at an e-waste dismantling area in Guiyu, Guangdong province, China [15]. The cells were inoculated and cultured in the nutrient broth at $30^{\circ} \mathrm{C}$ on a rotary shaker at a rotation speed of $100 \mathrm{r} / \mathrm{min}$ for $24 \mathrm{~h}$. The bacteria were then centrifuged at $6000 \times g$ and the cells were rinsed three-times with sterile $0.85 \% \mathrm{NaCl}$ solution.

\section{Intracellular uptake of SYTO 9 \& PI}

During the exponential growth phase, cells have higher metabolic activity and RNA content relative to other phases, which may affect PI staining results $[6,27]$. To avoid this issue, we used $B$. brevis cells in the stationary phase by growing them for a further $24 \mathrm{~h}$ before washing thrice with $0.85 \% \mathrm{NaCl}$ and resuspending them in the same solution. A schematic representation of the processing method and a flow cytometric graph of the negative and positive groups are shown in Supplementary Text 1 \& Supplementary Figure 1.

To establish the optimal dye concentrations, we stained the suspensions $\left(10^{6} \mathrm{cells} / \mathrm{ml}\right)$ with different concentrations of SYTO 9 $(0.25,0.75,1.5,2.5$ and $5.0 \mu \mathrm{M})$ and $\mathrm{PI}(1.5,4.5,9.0,15.0$ and $30.0 \mu \mathrm{M})$ at room temperature and then analyzed them by FCM. To assess the effect of excessive dye, we used higher concentrations of SYTO $9(5.0$ and $25.0 \mu \mathrm{M})$ and PI (18.0 and $90.0 \mu \mathrm{M})$. SYTO 9 and PI staining were analyzed by FCM (Gallios, Beckman Coulter) at a rate of $30 \mu \mathrm{l} / \mathrm{min}$ and the fluorescence signal was measured every 5 min (Supplementary Text 2)

\section{Live:dead bacterial mixtures verification}

Cells in the exponential growth phase (OD 0.6-0.8 at $600 \mathrm{~nm}$ ) were harvested by centrifugation at $6000 \times g$ for $10 \mathrm{~min}$ at $4{ }^{\circ} \mathrm{C}$. The bacterial pellet was resuspended in $0.85 \% \mathrm{NaCl}$ at room temperature. Aliquots of the resuspended cells were diluted in saline for live cell analysis, or $70 \%$ isopropanol for dead cell analysis (Supplementary Text 3 ).

\section{Extracellular monitoring of SYTO 9 \& PI uptake}

Standard curves were created using varying concentrations of dyes in which a binary mixture solution containing $5.0 \mu \mathrm{M}$ SYTO 9 and 18.0 $\mu \mathrm{M}$ PI was diluted to 2-, 3-, 4-, 8- and 16-times with $0.85 \% \mathrm{NaCl}$. The same volume of ultrapure water and dimethylsulfoxide were used as the blank group to eliminate the interference of dye solvents. Dye quantification was done by loading $1 \mu$ l of sample on Nan$\mathrm{oDrop}^{\mathrm{TM}}$ (One Microvolume Ultraviolet-visible (UV-Vis) Spectrophotometer, Thermo Fisher Scientific) and measuring absorbance at $240-$ $600 \mathrm{~nm}$. To describe the concentration of dyes in cell suspensions within $30 \mathrm{~min}$, each sample containing $10^{6} \mathrm{cells} / \mathrm{ml}$ and $3 \mu \mathrm{l}$ binary mixture solution was measured every $5 \mathrm{~min}$. Cells were obtained via centrifugation at $6000 \times g ; 1 \mu$ of the supernatant was obtained for spectrophotometric measurement and the remaining cells were resuspended in the same solution for further incubation. The above procedures were repeated six-times.

\section{Extraction \& determination of membrane fatty acids}

Fatty acid extraction was done as described previously (Supplementary Text 4) [28]. Bacterial acid methyl esters mix (SUPELCO) was used as the qualitative and quantitative standard (Supplementary Figure $3 \&$ Supplementary Table 2).

\section{Cell morphology}

Cell morphology before and after dye staining, was examined by scanning electronic microscopy (Philips $\mathrm{XL}-30 \mathrm{E})$. The samples were fixed in glutaraldehyde for $24 \mathrm{~h}$ and sequentially dehydrated in ethanol at 20, 50, 70, 90 and $100 \%(\mathrm{~V} / \mathrm{v})$. Then the samples were immersed in isoamyl acetate for $30 \mathrm{~min}$ before being dried at the breakthrough point using $\mathrm{CO}_{2}$ as a refrigerant. Subsequently, the samples were coated with gold to improve their conductivity and photographed by a scanning electron microscope.

\section{Statistical analyses}

Data are expressed as the mean \pm standard deviation. The flow cytometer graphs were produced with Kaluza analysis software. The curve fitting and correlation coefficient $\left(R^{2}\right)$ are calculated through Origin Pro $8^{\mathrm{TM}}$ software. 


\section{Results \& discussion}

\section{SYTO 9 or PI staining analysis}

First, we analyzed staining characteristics of the dyes by analyzing B. brevis cells stained with SYTO 9 and PI separately. The dyes permeated the cells, bound to DNA and RNA, and emitted light at different wavelengths upon 488-nm excitation. Changes of fluorescence intensity reflected intracellular staining kinetics for each dye. Figure $1 \mathrm{~A}$ shows the green fluorescence intensity distributions in cells stained with 0.25-5.0 $\mu \mathrm{M}$ SYTO 9. SYTO 9 immediately permeated the cell and combined with DNA/RNA, and the fluorescence intensity was proportional to increased dye concentration, although the relationship was not linear (Figure 1B). This indicated a decrease in the number of SYTO 9-positive cells due to an insufficient amount of the dye [29] and a high background signal due to excessive SYTO 9.

The red fluorescence PI-positive cells rose substantially in the first $5 \mathrm{~min}$ and continued to rise gradually before stabilizing after $25 \mathrm{~min}$ (Figure 1C), indicating that PI staining progresses slowly. The fluorescence intensities of the three concentrations (9, 15 and $30 \mu \mathrm{M})$ rose slowly after $30 \mathrm{~min}$ (Figure 1D), indicating that the dye had stained the membrane damaged cells. Insufficient or excessive PI staining caused changes in fluorescence intensity, consistent with the results of SYTO 9 staining.

The cells were stained with 2.5 and $5.0 \mu \mathrm{M}$ SYTO 9 to evaluate whether all cells were stained at these concentrations. The detection time at different cell numbers $\left(10,8,5,2,1 \times 10^{6} \mathrm{cells} / \mathrm{ml}\right)$ was evaluated. The relationship between the number of cells and detection time by FCM exhibited an identical fitted curve like the ones produced by staining with $2.5 \mu \mathrm{M}$ or $5.0 \mu \mathrm{M}$ SYTO 9 (Figure $1 \mathrm{E}$ \& Supplementary Table 1), indicating that both SYTO 9 concentrations entirely stained the cells. Thus $2.5 \mu \mathrm{M}$ was selected as the critical concentration for SYTO 9 staining and used in downstream analysis.

\section{Dual staining analysis}

To explore dye uptake during dual staining, varying concentrations of PI were added to cells stained with $2.5 \mu \mathrm{M}$ SYTO 9 (Figure 2). Analysis of intracellular fluorescence intensity over time showed that the two dyes competed for nucleic acids. The addition of four concentrations of $\mathrm{PI}(1.5,4.5,9.0$ and $15.0 \mu \mathrm{M})$ resulted in $23,30,41$ and $41 \%$ reduction in green fluorescence intensity respectively (Figure 2A). The change in fluorescence intensities over time at $620 \mathrm{~nm}$ is shown in Figure 2B. Staining with low concentrations of PI $(1.5$ and $4.5 \mu \mathrm{M})$ showed parallel fluorescence intensity variation; the fluorescence intensity of $4.5 \mu \mathrm{M} \mathrm{PI}$ was $20 \%$ higher than that of $1.5 \mu \mathrm{M}$ PI. The fluorescence intensity curves of 9.0 and $15.0 \mu \mathrm{M}$ PI had lower values than $4.5 \mu \mathrm{M}$ PI during dual staining.

The weakening of the green fluorescence intensity may be explained by two mechanisms: competitive displacement by PI's stronger nucleotide affinity targeting the same area, and fluorescence resonance energy transfer (FRET) [30]. SYTO 9's fluorescence intensity gradually fell in the presence of PI because the association constant of PI $\left(3.7 \times 10^{5} / \mathrm{M}\right)$ is higher than that of SYTO $9\left(1.8 \times 10^{5} / \mathrm{M}\right)[30$ ]. Moreover, because the emission bands of SYTO 9 and the absorption region of PI partially overlap, SYTO 9 transferred energy to PI (Figure S2). Considering that the uptake of PI is slow, gradually increasing interaction of PI and nucleic acids progressively weakened SYTO 9 fluorescence intensity. Similar trends at 9.0 and $15.0 \mu \mathrm{M}$ PI indicate that a similar effect. Moreover, the fluorescence intensity of SYTO 9 was barely changed after 10-min incubation.

Fluorescence intensities rose over time in the presence of $\mathrm{PI}$ alone and in dual staining tests, indicating that $\mathrm{PI}$ entry into the cells was slow. Lower concentrations of PI (1.5 and $4.5 \mu \mathrm{M})$ could entirely combine with DNA regardless of the unbound PI. However, an inadequate amount of PI meant that dead cells could not be totally stained, leading to a higher SYTO 9 fluorescence (Figure 2A). When the amount of DNA-bound PI increased but SYTO 9 was not completely replaced, the unutilized SYTO 9 acted as a donor, further improving FRET efficiency. Thus the fluorescence intensity of $4.5 \mu \mathrm{M} \mathrm{PI}$ was higher than that of other PI concentrations (Figure 2B). The competitive displacement behavior of PI was enhanced at higher concentrations, reducing the SYTO 9 fluorescence and even cutting down eliminated FRET. When PI was insufficient, FRET appeared to significantly influence PI intensity relative to competitive displacement, resulting in higher red fluorescence. PI at 9.0 and $15.0 \mu \mathrm{M}$ had similar fluorescence intensities after 20 -min incubation and combined completely with the dead cells' nucleic acids. Thus $9.0 \mu \mathrm{M}$ was selected as the optimal PI concentration for dual staining because of its low background signal and FRET efficiency.

To validate the effectiveness of $2.5 \mu \mathrm{M}$ SYTO 9 and $9.0 \mu \mathrm{M}$ PI staining, we tested these concentrations in a dual staining to identify the ratio of live to dead cells. As expected, the SYTO 9:PI intensity ratio had a linear relationship [31] with the proportions of live cells in the samples (Figure 2C), indicating that $9.0 \mu \mathrm{M}$ PI stains all damaged cells, and that the dynamic processes of nucleic acid binding and releasing by SYTO 9 and PI are balanced in suspension. After staining using the optimal conditions, the proportion of live cells in suspension can be calculated from the SYTO 9:PI intensity ratio.

Next, the fitted linear relationship was used to verify the results seen in cells stained with $2.5 \mu \mathrm{M}$ SYTO 9 and $9.0 \mu \mathrm{M}$ PI, including the suitability of these concentrations and the time required for the SYTO 9:PI intensity ratio to remain stable. The SYTO 9:PI intensity ratio obtained by substituting the number of detected live cells into the fitted linear equation was then compared with that measured by FCM (Figure 2D). In the initial $10 \mathrm{~min}$, the calculated ratio was greater than the detected ratio due to the incomplete PI staining, increasing the number of 'live cells', but the ratio became equalized in the next $20 \mathrm{~min}$. In summary, the data generated by staining $10^{6}$ cells $/ \mathrm{ml}$ with $2.5 \mu \mathrm{M}$ SYTO 9 and $9.0 \mu \mathrm{M}$ PI for 10 min were reliable.

We then used FCM to analyze SYTO 9/PI overstaining versus normal staining (Figure 2E \& F). In the dual staining, relative to solo SYTO 9 staining, SYTO 9 fluorescence intensity decreased as its concentration increased (Figure 2E). Inclusion of SYTO 9 promoted PI uptake, resulting in higher numbers of 'dead cells' and enhanced PI fluorescence intensity (Figure 2F), suggesting that SYTO 9 alters 
(A)

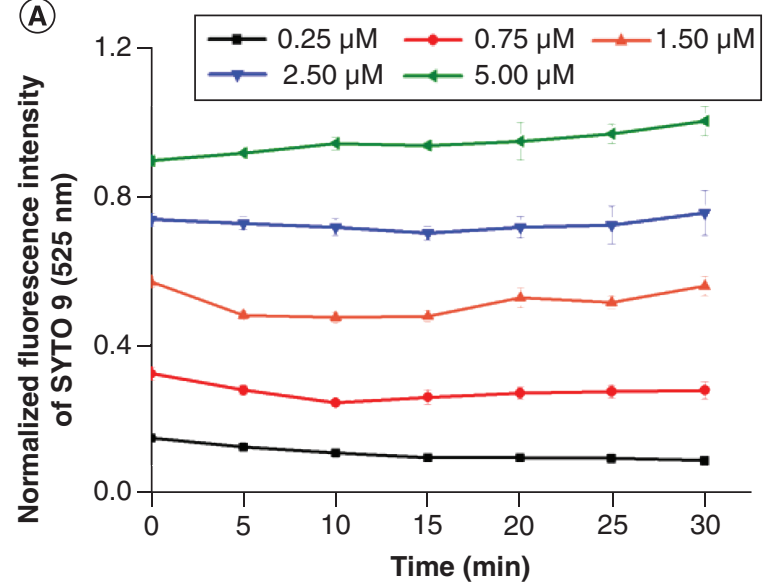

(C)

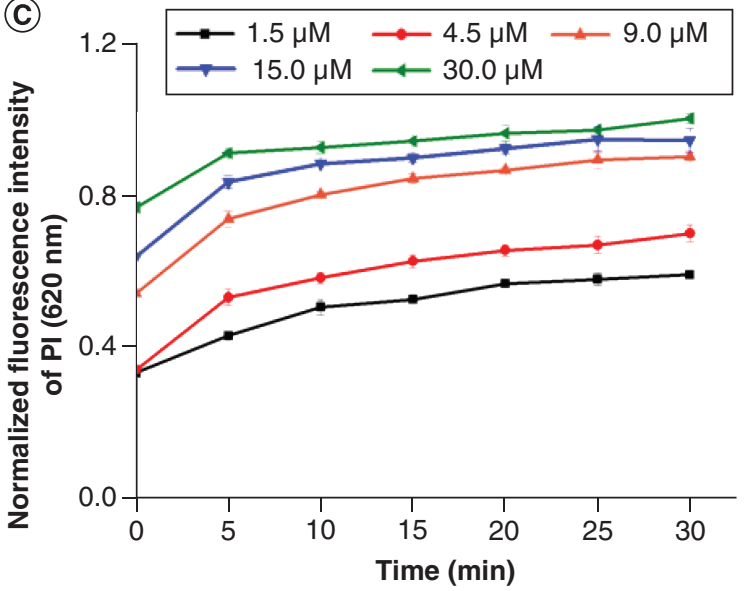

(B)

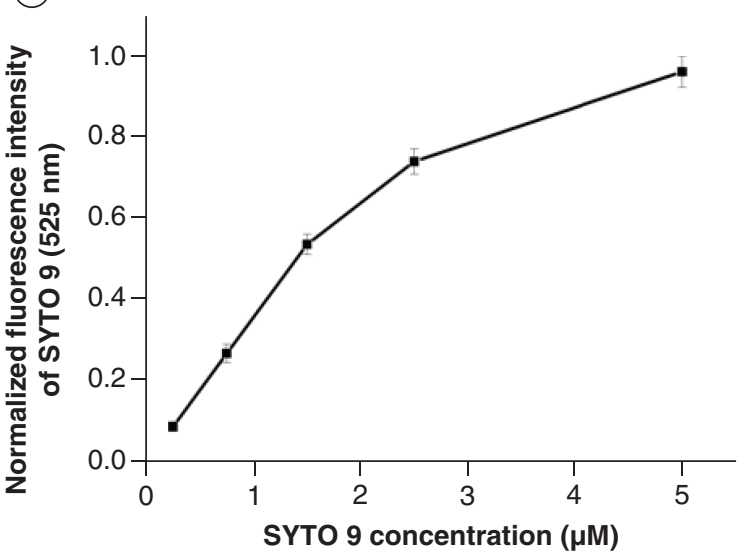

(D)

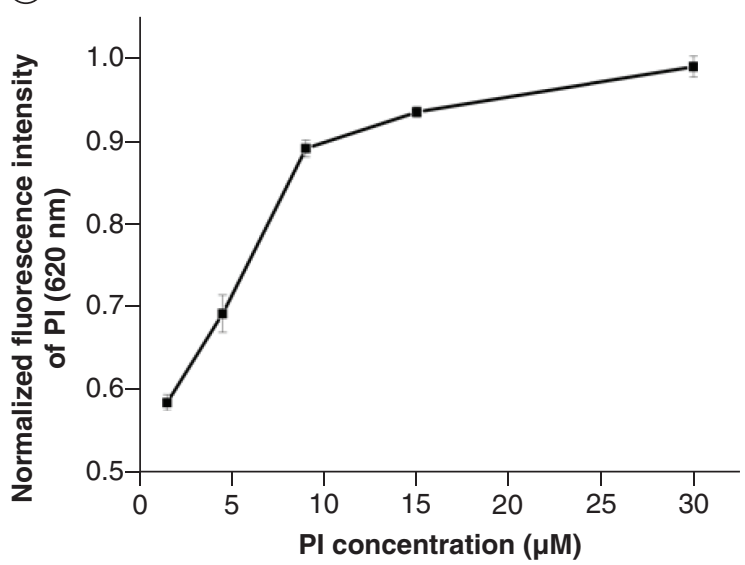

(E)

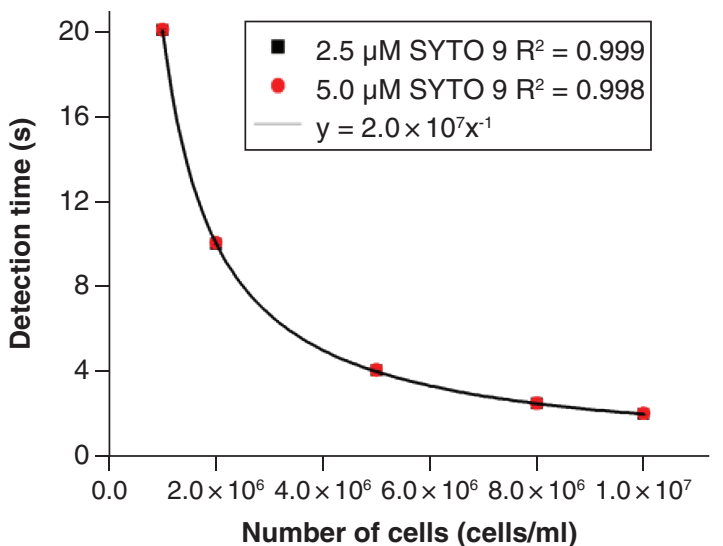

Figure 1. Analysis of cells stained with different concentrations of SYTO 9 and PI alone using FCM. (A \& C) show changes in the fluorescence intensity over time after staining with varying concentrations of SYTO 9 and PI. (B \& D) show the relative fluorescence intensity (RFU) with different concentrations of SYTO 9 and PI at $30 \mathrm{~min}$. (E) shows the detection time as a function of the number of cells. Error bars represent standard deviations $(n=3)$. Experimental conditions: solution temperature $25 \pm 2{ }^{\circ}$, cell density $10^{6} \mathrm{cells} / \mathrm{ml}$.

PI: Propidium iodide. 

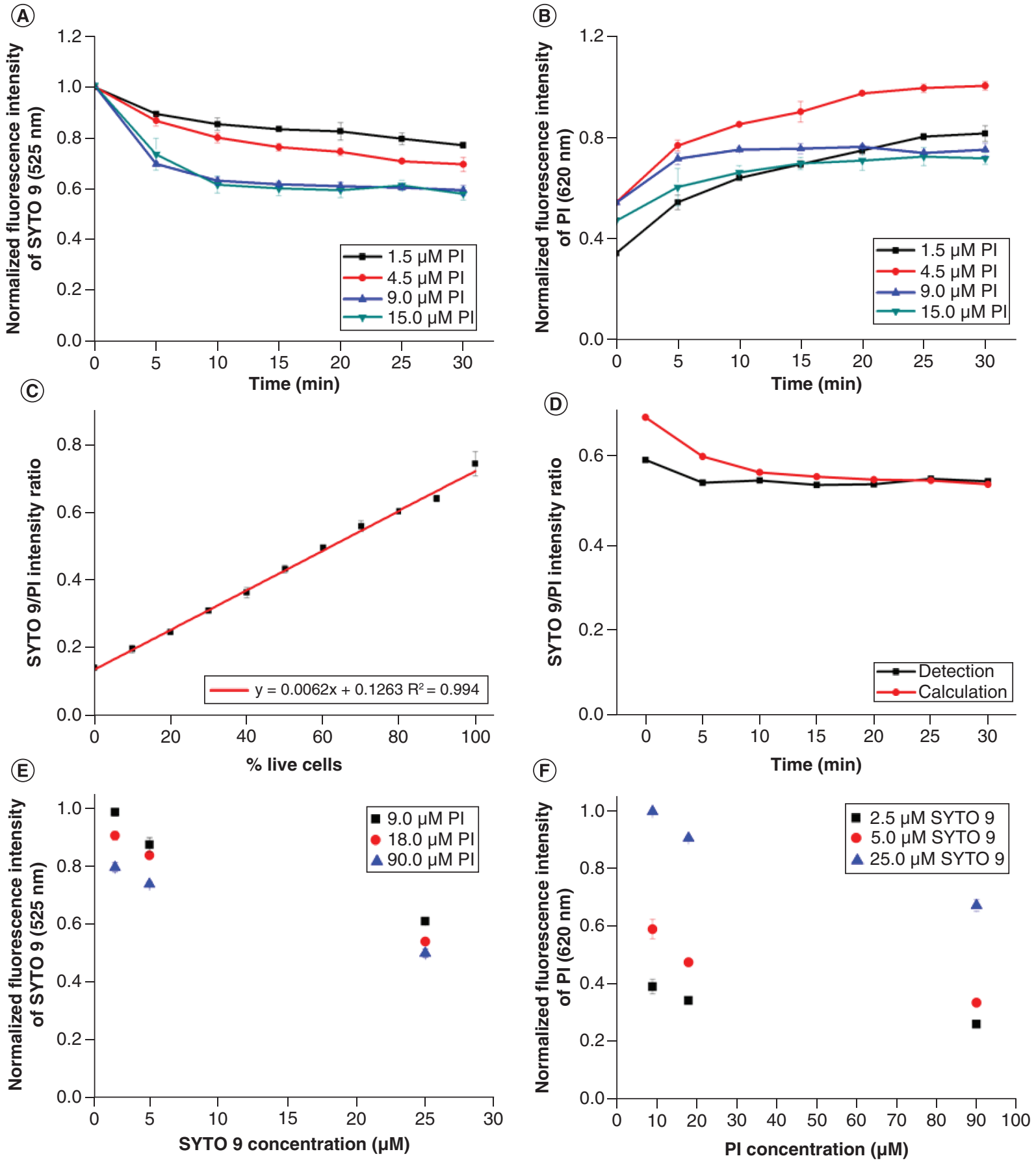

Figure 2. Changes in the fluorescence intensity for cells stained with $2.5 \mu \mathrm{M}$ SYTO 9 and varying concentrations of PI. (A \& B) show the intensities of red fluorescence recovered at wavelengths 525 and $620 \mathrm{~nm}$ respectively. (C) shows the SYTO 9:PI intensity ratio as a function of the percentage of live cells in the training samples. (D) shows the SYTO 9:PI intensity ratios of detection and calculation values in $2.5 \mu \mathrm{M}$ SYTO 9 and $9.0 \mu \mathrm{M}$ PI stained samples. (E \& F) show the fluorescence intensities of SYTO 9 and PI under dual staining with varying dye concentrations. Error bars represent standard deviations $(n=3)$. Experimental conditions: solution temperature $25 \pm 2^{\circ} \mathrm{C}$, cell density $10^{6}$ cells $/ \mathrm{ml}$. PI: Propidium iodide. 
membrane physicochemical properties, allowing easier PI entry. At the same SYTO 9 concentrations, increasing PI staining also reduced the SYTO 9 fluorescence intensity, partly because of excessive PI bound to nucleic acids; another reason may be that PI adhered to the membranes and weakened both dyes' signals. Notably, the background signal of PI should be considered during dual staining, because excessive PI not bound to nucleic acids caused relatively low red fluorescence and diluted PI fluorescence intensities. Consequently, dual staining should use optimal dye concentrations to avoid interference from background signals.

\section{SYTO 9/PI staining kinetics}

Variations in dye concentration may provide an external view of the uptake process. The absorbance spectra of the dyes, alone or in combination at $2.5 \mu \mathrm{M}$ SYTO 9 and $9.0 \mu \mathrm{M}$ PI, indicated a significant overlap when combined, while the maximum wavelengths for SYTO 9 and PI were 480 and $280 \mathrm{~nm}$, respectively (Figure 3A). Derivative spectrometry can reduce interference between two or more spectra [32]; hence the absorbance spectra of SYTO 9 and PI in single and binary solutions were analyzed using Origin Pro 8.

First-order derivatives of the single or combined dyes (Figure 3B) showed that when either SYTO 9 or PI was regarded as the target compound, the first-order derivative value of the other component was close to 0 ; the optimal linear response and calibration graphs of the compound were not affected by the concentration of other components. The first-order derivative absorbance spectra for dyes in binary solution showed that the optimal wavelengths for SYTO 9 and PI detection were 481.5 and $282.5 \mathrm{~nm}$, respectively.

Next, the binary solutions' absorption spectra were plotted after assessing their concentrations (Figure 3C) and used to calculate their first-order derivative value at the optimal wavelengths. These values were used to depict calibration curves for SYTO 9 and PI (binary solutions) quantification, and their correlation coefficients $\left(\mathrm{R}^{2}\right)$ (Figure 3D \& E). The excellent and wide linear range, equations, and acceptable $R^{2}$ verified that the selected wavelengths were optimal for the calculation of SYTO 9 and PI concentrations. Thus the quantification of SYTO 9 and PI can be derived from the first-order derivative spectrum of binary dye solution at wavelengths 282.5 and $481.5 \mathrm{~nm}$.

Next, $10^{6}$ cells $/ \mathrm{ml}$ (B. brevis) were stained with $2.5 \mu \mathrm{M}$ SYTO 9 and $9.0 \mu \mathrm{M}$ PI and the absorption spectra of binary dyes measured over time (Figure 4A). Changes in dye concentration were evaluated after 30 min using their first-order derivative values and the calibration curve as mentioned above (Figure 4B). The concentration of SYTO 9 was found to decrease slowly with time; it stabilized after 15 min and remained at $50 \%$ after $30 \mathrm{~min}$. The PI concentration fell by more than $78 \%$ in 5 min and reduced to about $0.2 \mu \mathrm{M}$ in the next $25 \mathrm{~min}$.

These results indicated that the intracellular concentration of SYTO 9 was limited by its starting concentration, consistent with passive diffusion [33,34]. To get accurate results, a sufficient concentration of dye that does not affect normal cellular physiology is therefore needed. Moreover, when used together with PI, SYTO 9 entry into the cells was slow. The weaker fluorescence intensity during dual staining may have resulted from competitive displacement of PI, which may have enhanced the attenuated SYTO 9 fluorescence intensity.

PI does not cross an intact membrane because of its size and charge [2]. However, the 55.9- $\AA^{2}$ topological polar surface area of $\mathrm{PI}$ might pass through the $70-\AA$ diameter pore of peptidoglycan. Additionally, the double charge of the propidium ion may enhance PI's adherence to the cell wall, rapidly reducing PI concentration in suspension (Figure 4B). Brognaux et al. reported that transport and binding proteins induced by substrate limitation facilitate PI entry into cells [35], suggesting that the restriction of PI translocation is due to membrane properties including permeability and potential, rather than the extracellular PI concentration. This may explain why the concentration of extracellular PI decreased rapidly but intracellular fluorescence stayed relatively stable.

\section{Phospholipid synthesis after excessive SYTO 9/PI staining}

Phospholipids, the major constituent of cell membranes, require fatty acids for their synthesis. The composition and content of fatty acids depend on the various substances transported across biological membranes [36,37]. To study changes in phospholipid synthesis in response to SYTO 9 and PI, we compared the composition and content of membrane fatty acids in $B$. brevis cells exposed to excessive and optimal amounts of SYTO 9 and PI for 30 min (Figure 5 \& Supplementary Table 3).

The main fatty acids in $B$. brevis membranes include lauric acid (C12:0), myristic acid (C14:0), pentadecanoic acid (C15:0), palmitic acid (C16:0), heptadecanoic acid (C17:0) and stearic acid (C18:0), which are saturated; and oleic acid methyl ester (C18:1n9c), linolelaidic acid methyl ester (C18:2n6c) and erucic acid methyl ester (C22:1n9), which are unsaturated (UFA) (Figure 5A).

The total fatty acid content increased significantly in high dye concentration (Figure $5 \mathrm{~A}$ ). It has been suggested that this is because the bacteria promote the uptake of molecules by elevating fatty acid content [38]. Rigidification of cell membranes through increased long-chain fatty acid content is an adaptive mechanism in bacteria [39]. Marked alterations of C16:0 and C18:0 may be responsible for the observed membrane integrities.

The composition and content of the UFAs are shown in Figure 5B. SYTO 9 and $90 \mu \mathrm{M}$ PI promoted the synthesis of C18:2n6c, which reached concentrations of close to $0.19 \mathrm{~g} / \mathrm{I}$. In the presence of excessive SYTO 9 or PI, bacterial cell membranes showed an apparent increase in UFA, with high levels of C18:1n9c and C18:2n6c. UFAs have lower melting points than saturated fatty acids, which are more suitable for plasma membrane permeability [40]. Thus UFAs alter membrane permeability and impact membrane potential, which may enhance PI entry and lead to cells being marked as dead [41,42]. Taken together, these results show that phospholipid synthesis facilitates membrane transport in staining conditions and that excessive SYTO 9 and PI may give erroneous results and even affect cell physiology. Alterations in membrane physicochemical properties may have enhanced dye binding to the surface membrane and facilitated dye entry. 

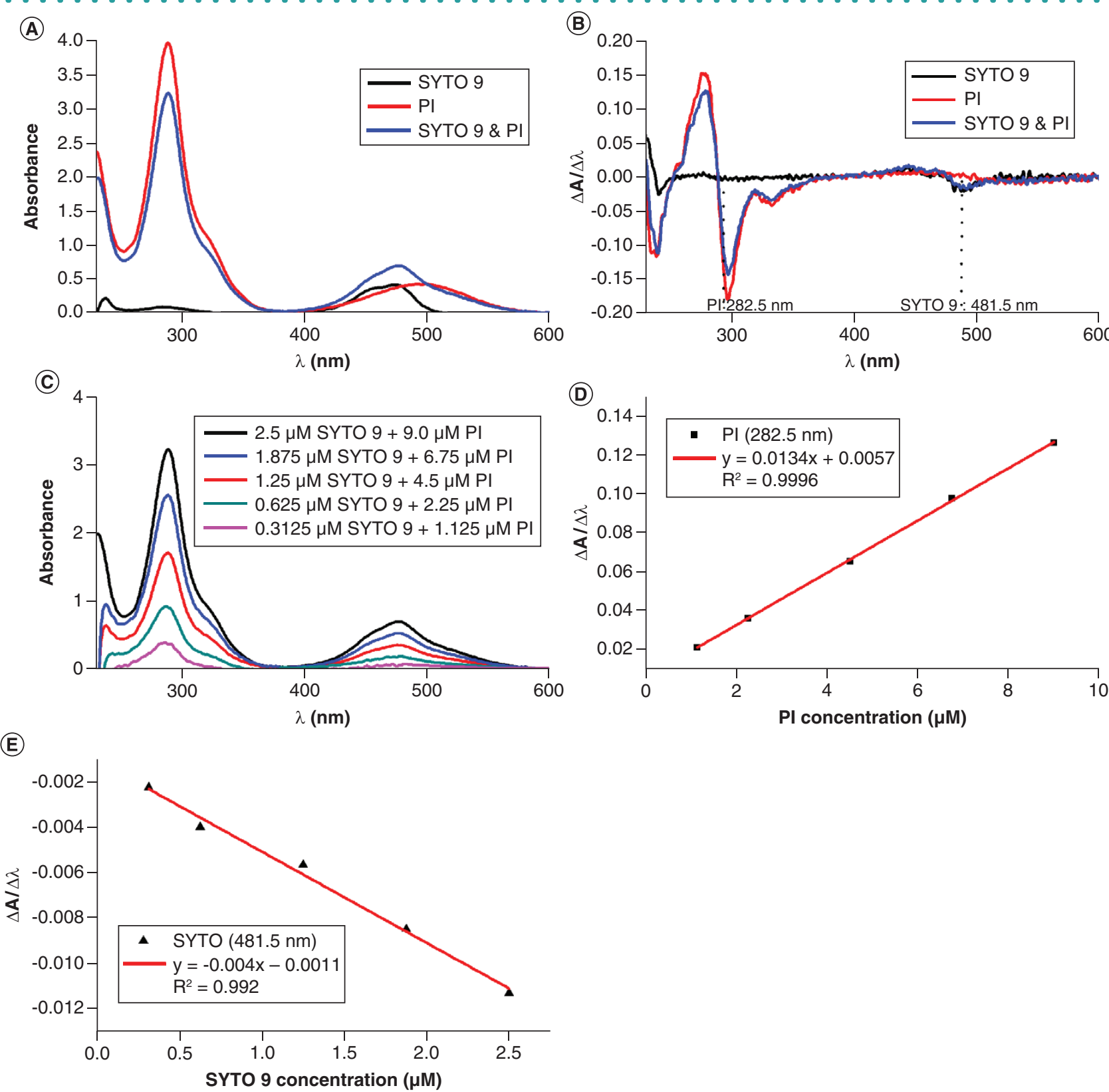

Figure 3. Quantification of SYTO 9 and PI. (A) Zero-order absorption spectra and (B) first-order derivative spectra of SYTO 9 and PI dyes in single and binary solution (initial dye concentrations 2.5 and $9.0 \mu \mathrm{M}$ for SYTO 9 and PI, respectively). (C) Zero-order absorption spectra of binary mixture. (D) Calibration curve of PI in range 1.125-9.0 $\mu \mathrm{M}$. (E) Calibration curve of SYTO 9 in range $0.3125-2.5 \mu \mathrm{M}$.

Experimental conditions: solution temperature $25 \pm 2{ }^{\circ} \mathrm{C}, \mathrm{pH} 6.5-7.2$. PI: Propidium iodide.

\section{Cell morphology after excessive SYTO 9/PI staining}

To validate cell morphology changes in the presence of excessive dye amounts, we examined the cells by scanning electronic microscopy (Figure 6). This analysis revealed that cells subjected to $2.5 \mu \mathrm{M}$ SYTO 9 and $9.0 \mu \mathrm{M}$ PI did not show significant morphological changes relative to control cells (Figure 6A \& B), suggesting that the dyes do not significantly affect the optimal staining conditions for the cells. The cells exhibited a plump shape and an intact, smooth cell wall, which is essential for normal cellular metabolic activities and transport [43].

To assess the effects of excessive dye levels, the cells were subjected to high SYTO 9 and PI concentrations and their morphology was examined by scanning electronic microscopy. Due to the inert nature of the cyanine SYTO probes [44], the surfaces of cells subjected 


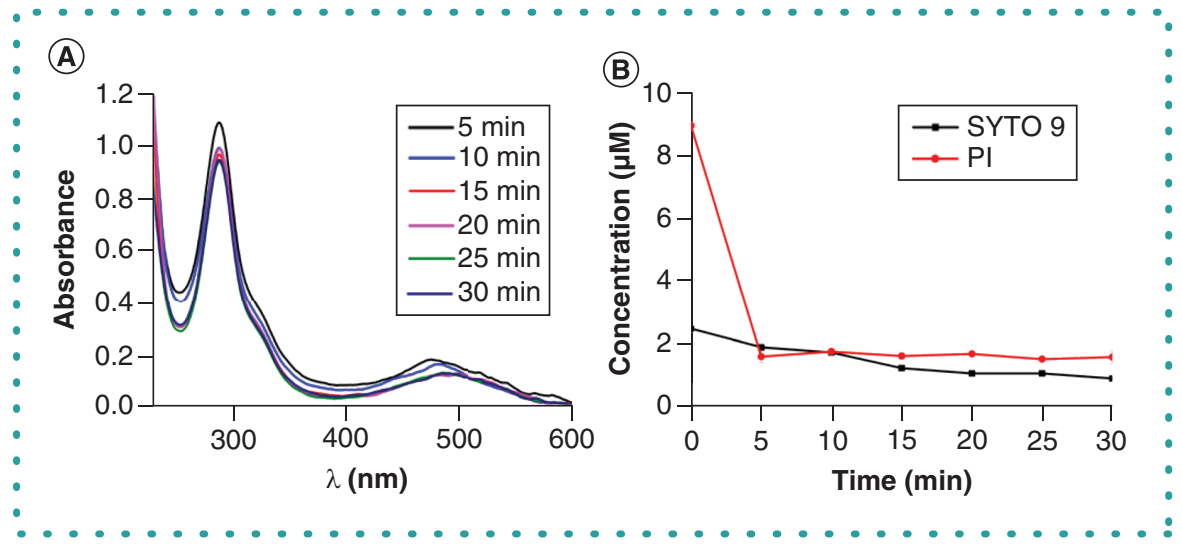

Figure 4. Variation in the absorption spectra and concentration of binary dyes. (A) Zero-order absorption spectra of $2.5 \mu \mathrm{M}$ SYTO 9 and $9.0 \mu \mathrm{M}$ PI. (B) Concentration of SYTO 9 and PI in the supernatant.

Experimental conditions: solution temperature $25 \pm 2^{\circ} \mathrm{C}, \mathrm{pH} 6.5-7.2$, cell density $10^{6}$ cells $/ \mathrm{ml}$. PI: Propidium iodide.

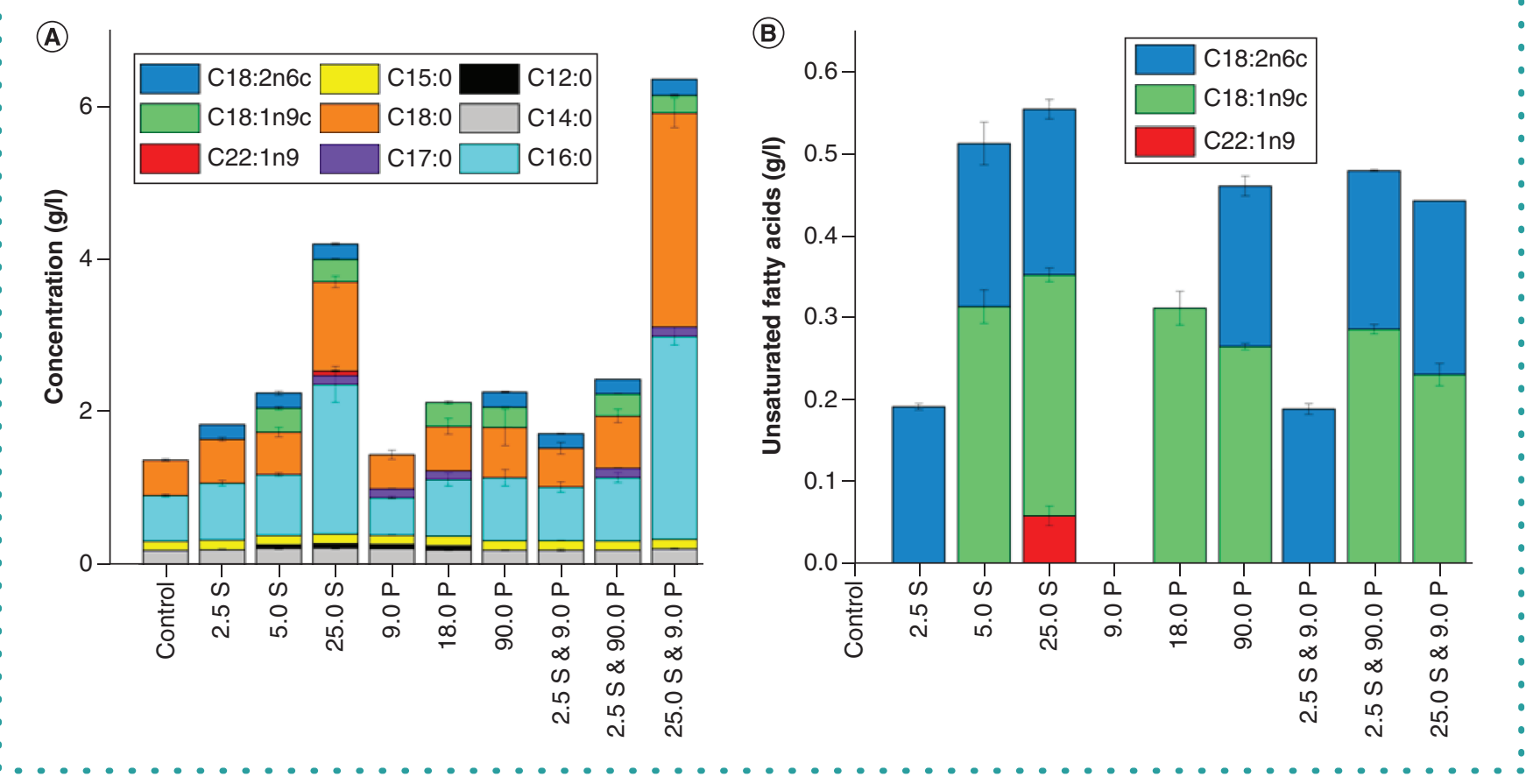

Figure 5. Changes in fatty acid composition and content in cells exposed to SYTO 9 and PI. (A) Composition and content of total fatty acids. (B) Composition and content of unsaturated fatty acids. S represents SYTO 9 dye, and P represents PI dye. The concentration of dyes added was expressed in $\mu \mathrm{M}$. Error bars represent standard deviations $(n=3)$.

PI: Propidium iodide.

to $25.0 \mu \mathrm{M}$ SYTO 9 showed subtle changes after dye uptake (Figure $6 \mathrm{C} \& \mathrm{D}$ ). In contrast, the membranes of cells subjected to $90.0 \mu \mathrm{M}$ PI were clearly aberrant, exhibiting cytoadherence; this observation is consistent with a large amount of PI adsorption to the cell wall, as suspected (Figure 6E \& F). Because the dyes are all positively charged, and especially given that PI has two positive charges, the apparent morphological changes of cells exposed to the dyes may be due to electrostatic forces.

In summary, we have optimized a SYTO 9/PI staining method for characterizing cell viability using FCM by exploring the interplay, kinetics and impact on $B$. brevis of the two dyes. Both SYTO 9 and PI signals were affected by FRET and background signals. We found that, to minimize interference, the optimal SYTO 9 and PI concentrations were 2.5 and $9.0 \mu \mathrm{M}$ respectively for a sample of $10^{6}$ cells $/ \mathrm{ml}$. These dye concentrations are not toxic to the cells. For a sample size of $<10^{7}$ cells $/ \mathrm{ml}, 2.5 \mu \mathrm{M}$ SYTO 9 and $9.0 \mu \mathrm{M}$ PI are still sufficient. However, for larger sample sizes, the cell number may exceed the upper limit of FCM, limiting accuracy. We used derivative spectrometry to assess SYTO 9/PI staining kinetics and observed that SYTO 9 penetrates the cells continuously while PI entry occurs 

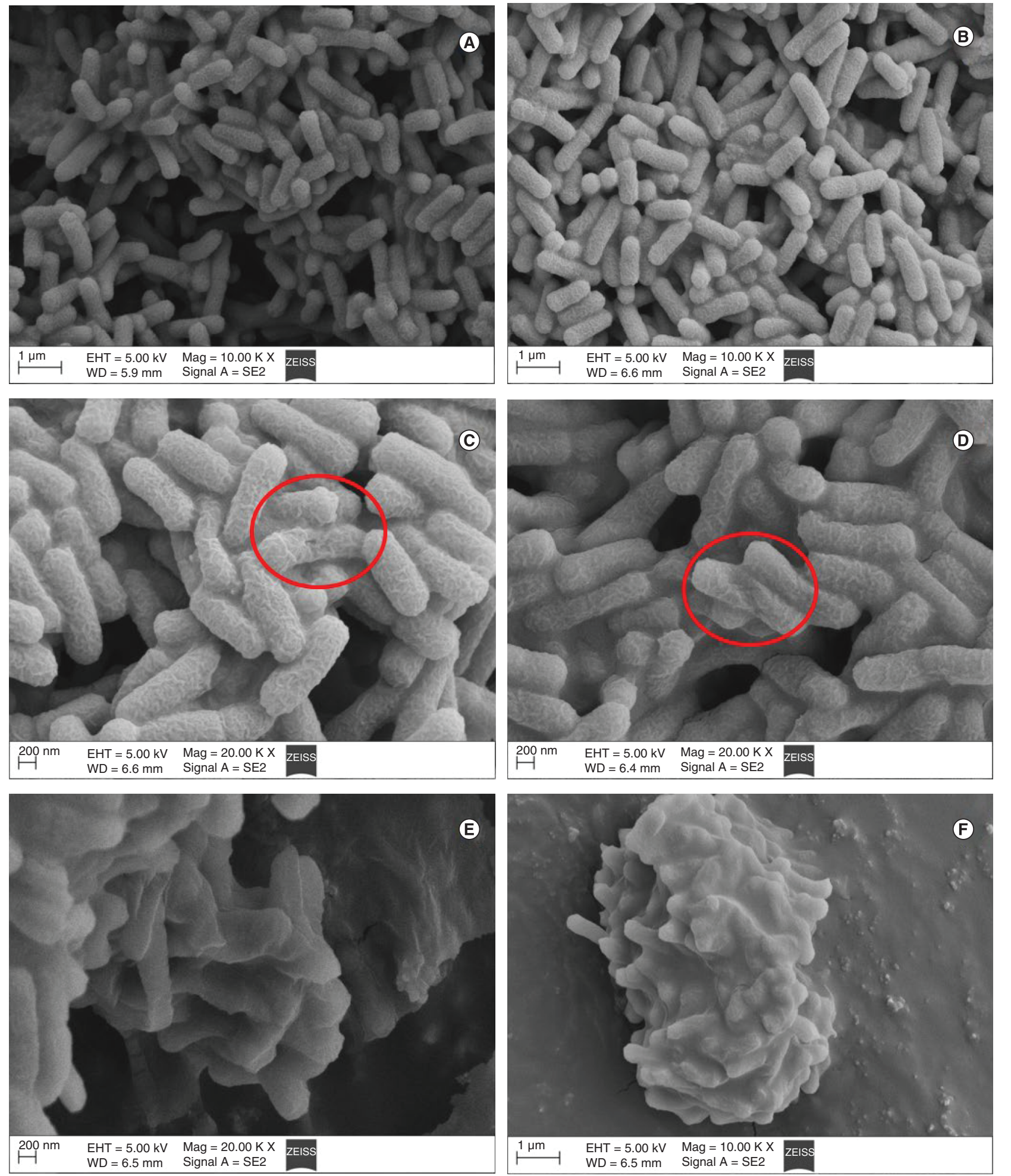

Figure 6. Surface morphology of Brevibacillus brevis. (A) Control cells. (B) $2.5 \mu \mathrm{M}$ SYTO 9 and $9.0 \mu \mathrm{M}$ PI staining. (C) $25.0 \mu \mathrm{M}$ SYTO 9 staining. (D) $25.0 \mu \mathrm{M}$ SYTO 9 and $9.0 \mu \mathrm{M}$ PI staining. (E) $90.0 \mu \mathrm{M}$ PI staining. (F) $2.5 \mu \mathrm{M}$ SYTO 9 and $90.0 \mu \mathrm{M}$ PI staining. Experimental conditions: solution temperature $25 \pm 2{ }^{\circ} \mathrm{C}, B$. brevis density $10^{6}$ cells $/ \mathrm{ml}$. PI: Propidium iodide. 
slowly by cytoadherence. Additionally, high dye amounts may alter cell membrane properties and promote membrane transport, leading to erroneous results.

\section{Future perspective}

This study offers insights into the mechanisms of SYTO 9 and PI uptake kinetics and how the dyes impact $B$. brevis, laying the foundation for future work on the use of flow cytometry to assess bacterial viability. Different bacterial staining methods should be optimized to maximize assay accuracy.

\section{Supplementary data}

To view the supplementary data that accompany this paper please visit the journal website at: www.futurescience.com/doi/suppl/10.2144/btn-2020-0036

\section{Author contributions}

Y Long helped in the design of this project. Y Deng performed the experimentation and wrote the draft of this manuscript. $Y$ Chen analyzed the associated data. $L$ Wang provided input and contributed to the writing of the manuscript.

\section{Financial \& competing interests disclosure}

The authors would like to thank the National Key Research and Development Project of China (no. 2017YFD0801300) and the Science and Technology Project of Guangdong province (no. 2016B02024007) for their financial support. The authors have no other relevant affiliations or financial involvement with any organization or entity with a financial interest in or financial conflict with the subject matter or materials discussed in the manuscript apart from those disclosed.

No writing assistance was utilized in the production of this manuscript.

\section{Open access}

This work is licensed under the Attribution-NonCommercial-NoDerivatives 4.0 Unported License. To view a copy of this license, visit http: //creativecommons.org/licenses/by-nc-nd/4.0/

\section{References}

1 Ou F, McGoverin C, Swift S, Vanholsbeeck F. Rapid and cost-effective evaluation of bacterial viability using fluorescence spectroscopy. Anal. Bioanal. Chem. 411(16), 3653-3663 (2019).

2 Buysschaert B, Byloos B, Leys N, Van Houdt R, Boon N. Reevaluating multicolor flow cytometry to assess microbial viability. Appl. Microbiol. Biotechnol. 100(21), 9037-9051 (2016).

3 Deligeorgiev TG, Kaloyanova S, Vaquero JJ. Intercalating cyanine dyes for nucleic acid detection. Recent Pat. Mater. Sci. 2(1), 1-26 (2009).

4 Stiefel P, Schmidt-Emrich S, Maniura-Weber K, Ren Q. Critical aspects of using bacterial cell viability assays with the fluorophores SYTO9 and propidium iodide. BMC Microbiol. 15(1), 36 (2015).

5 Shi L, Günther S, Hübschmann T, Wick LY, Harms H, Müller S. Limits of propidium iodide as a cell viability indicator for environmental bacteria. Cytometry A 71(8), 592-598 (2007).

6 Barbesti S, Citterio S, Labra M, Baroni MD, Neri MG, Sgorbati S. Two and three-color fluorescence flow cytometric analysis of immunoidentified viable bacteria. Cytometry 40(3), 214-218 (2000).

7 Munukka E, Leppäranta O, Korkeamäki M et al. Bactericidal effects of bioactive glasses on clinically important aerobic bacteria. J. Mater. Sci. Mater. Med. 19(1), 27-32 (2008).

8 Larrosa M, Truchado P, Espín JC, Tomás-Barberán FA, Allende A, García-Conesa MT. Evaluation of Pseudomonas aeruginosa (PA01) adhesion to human alveolar epithelial cells A549 using SYTO 9 dye. Mol. Cell. Probes 26(3), 121-126 (2012).

9 Berney M, Hammes F, Bosshard F, Weilenmann HU, Egli T. Assessment and interpretation of bacterial viability by using the LIVE/DEAD BacLight Kit in combination with flow cytometry. Appl. Environ. Microbiol. 73(10), 3283-3290 (2007).

10 Kim SJ, Chang J, Singh M. Peptidoglycan architecture of Gram-positive bacteria by solid-state NMR. Biochimica Biophysica Acta 1848(1), 350-362 (2015).

11 Zhu Y, Chen K, Ding Y, et al. Metabolic and proteomic mechanism of benzo [a] pyrene degradation by Brevibacillus brevis. Ecotoxicol. Environ. Saf. 172, 1-10 (2019).

12 Wei K, Yin H, Peng H, Liu Z, Lu G, Dang Z. Characteristics and proteomic analysis of pyrene degradation by Brevibacillus brevis in liquid medium. Chemosphere 178, 80-87 (2017).

13 Liu Y, Yin H, Wei K, Peng H, Lu G, Dang Z. Biodegradation of tricresyl phosphate isomers by Brevibacillus brevis: degradation pathway and metabolic mechanism. Chemosphere 232, 195-203 (2019).

14 Tang S, Bai J, Yin H et al. Tea saponin enhanced biodegradation of decabromodiphenyl ether by Brevibacillus brevis. Chemosphere 114, 255-261 (2014).

15 Ye J, Yin H, Peng H, Bai J, Xie D, Wang L. Biosorption and biodegradation of triphenyltin by Brevibacillus brevis. Bioresour. Technol. 129, 236-241 (2013).

16 Wilkinson MG. Flow cytometry as a potential method of measuring bacterial viability in probiotic products: a review. Trends Food Sci. Technol. 78, 1-10 (2018).

17 Fontana C, Crussard S, Simon-Dufay N, Pialot D, Bomchil N, Reyes J. Use of flow cytometry for rapid and accurate enumeration of live pathogenic Leptospira strains. J. Microbiol. Methods 132, 34-40 (2017).

18 Jitian S, White SR, Yang HHW, Weisz A. Conventional high-performance liquid chromatography versus derivative spectrophotometry for the determination of 1,3,6-pyrenetrisulfonic acid trisodium salt and 1,3,6,8-pyrenetetrasulfonic acid tetrasodium salt in the color additive D\&C Green No. 8 (Pyranine). J. Chromatogr. A 1324, 238-241 (2014).

19 Hu Z, Qi P, Wang N et al. Simultaneous determination of multiclass illegal dyes with different acidic-basic properties in foodstuffs by LC-MS/MS via polarity switching mode. Food Chem. $309,125745(2020)$.

20 El-Sheikh AH, Al-Degs YS. Spectrophotometric determination of food dyes in soft drinks by second order multivariate calibration of the absorbance spectra-pH data matrices. Dyes Pigm. 97(2), 330-339 (2013).

21 Ghaedi M, Hajati S, Barazesh B, Karimi F, Ghezelbash G. Saccharomyces cerevisiae for the biosorption of basic dyes from binary component systems and the high order derivative spectrophotometric method for simultaneous analysis of Brilliant green and Methylene blue. J. Ind. Eng. Chem. 19(1), 227-233 (2013).

22 Dil EA, Ghaedi M, Asfaram A. Optimization and modeling of preconcentration and determination of dyes based on ultrasound assisted-dispersive liquid-liquid microextraction coupled with derivative spectrophotometry. Ultrason. Sonochem. 34, 27-36 (2017).

23 Hussein JS. Cell membrane fatty acids and health. Int. J. Pharm. Pharm. Sci. 5(3), 38-46 (2013).

24 Dubois-Brissonnet F, Trotier E, Briandet R. The biofilm lifestyle involves an increase in bacterial membrane saturated fatty acids. Front. Microbiol. 7, 1673 (2016).

25 Burns CP, Luttenegger DG, Dudley DT, Buettner GR, Spector AA. Effect of modification of plasma membrane fatty acid composition on fluidity and methotrexate transport in L1210 murine leukemia cells. Cancer Res. 39(5), 1726-1732 (1979). 
26 Ruiz-Gutierrez V, Stiefel P, Villar J, Garcia-Donas MA, Acosta D, Carneado J. Cell membrane fatty acid composition in type 1 (insulin-dependent) diabetic patients: relationship with sodium transport abnormalities and metabolic control. Diabetologia 36(9), 850-856 (1993).

27 Bremer HDPP, Dennis PP. Modulation of chemical composition and other parameters of the cell by growth rate. EcoSal Plus 2(2), 1553-1569 (1996).

28 Schutter ME, Dick RP. Comparison of fatty acid methyl ester (FAME) methods for characterizing microbial communities. Soil Sci. Soc. Am. J. 64(5), 1659-1668 (2000).

29 Maecker HT, Frey T, Nomura LE, Trotter J. Selecting fluorochrome conjugates for maximum sensitivity. Cytometry A 62(2), 169-173 (2004).

30 Stocks SM. Mechanism and use of the commercially available viability stain, BacLight. Cytometry A 61(2), 189-195 (2004).

31 Probes M. LIVE/DEAD BacLight bacterial viability kits. Fluorescence Spectroscopy Protocols. Staining Bacteria with either Kit L7007 or L, 2004. 7012 . www.thermofisher.com/order/cata log/product/L7007\#/L7007

32 Coelho TM, Vidotti EC, Rollemberg MC et al. Photoacoustic spectroscopy as a tool for determination of food dyes: comparison with first derivative spectrophotometry. Talanta 81(1-2), 202-207 (2010).

33 Avalos Vizcarra I, Emge P, Miermeister P et al. Fluorescence-based in situ assay to probe the viability and growth kinetics of surface-adhering and suspended recombinant bacteria. Biointerphases 8(1), 22 (2013).

34 Wlodkowic D, Skommer J, Faley S, Darzynkiewicz Z, Cooper JM. Dynamic analysis of apoptosis using cyanine SYTO probes: from classical to microfluidic cytometry. Exp. Cell Res. 315(10), 1706-1714 (2009).

35 Brognaux A, Francis F, Twizere JC, Thonart P, Delvigne F. Scale-down effect on the extracellular proteome of Escherichia coli: correlation with membrane permeability and modulation according to substrate heterogeneities. Bioprocess Biosyst. Eng. 37(8), 1469-1485 (2014).

36 Van Meer G, Voelker DR, Feigenson GW. Membrane lipids: where they are and how they behave. Nat. Rev. Mol. Cell Biol. 9(2), 112-124 (2008).

37 Green DE, Fry M, Blondin GA. Phospholipids as the molecular instruments of ion and solute transport in biological membranes. Proc. Natl Acad. Sci. USA 77(1), 257-261 (1980).

38 Bažulić D, Najdek M, Pavoni B, Orio AA. PCB effects on production of carbohydrates, lipids and proteins in marine diatom Phaeodactylum tricornutum. Comp. Biochem. Physiol. C: Comp. Pharmacol. 91(2), 409-412 (1988).

39 Cummings SP, Russell NJ. Osmoregulatory responses of bacteria isolated from fresh or composted, olive-mill waste-waters. World J. Microbiol. Biotechnol. 12(1), 61-67 (1996).

40 Zhukova NV, Aizdaicher NA. Fatty acid composition of 15 species of marine microalgae. Phytochemistry 39(2), 351-356 (1995).

41 Kirchhoff C, Cypionka H. Propidium ion enters viable cells with high membrane potential during live-dead staining. J. Microbiol. Methods 142, 79-82 (2017).

42 Oyanagi E, Yano H, Kato Y, Fujita H, Utsumi K, Sasaki J. L-Carnitine suppresses oleic acid-induced membrane permeability transition of mitochondria. Cell Biochem. Func. 26(7), 778-786 (2008).

43 Tang L, Wang L, Ou H, Li Q, Ye J, Yin H. Correlation among phenyltins molecular properties, degradation and cellular influences on Bacillus thuringiensis in the presence of biosurfactant. Biochem. Eng. J. 105, 71-79 (2016).

44 Wlodkowic D, Skommer J, Darzynkiewicz Z. Rapid quantification of cell viability and apoptosis in B-cell lymphoma cultures using cyanine SYTO probes. In: Mammalian Cell Viability. Humana Press, 81-89 (2011). 
